Revista de la red interuniversitaria de estudios sobre las literaturas rioplatenses contemporáneas en Francia

23 | 2021

La vereda de enfrente. Cruces entre las literaturas argentina y chilena del siglo $\mathrm{XX}$

\title{
Escribir la historia de los futuros del pasado
}

Ecrire l'histoire des futurs du passé

Writing the History of the Futures of the Past

\section{Patrick Boucheron}

Traductor: Cecilia González

\section{(2) OpenEdition}

\section{Journals}

Edición electrónica

URL: https://journals.openedition.org/lirico/11794

DOI: $10.4000 /$ lirico. 11794

ISSN: 2262-8339

Editor

Réseau interuniversitaire d'étude des littératures contemporaines du Río de la Plata

\section{Referencia electrónica}

Patrick Boucheron, «Escribir la historia de los futuros del pasado», Cuadernos LIRICO [En línea], 23 |

2021, Publicado el 09 diciembre 2021, consultado el 07 enero 2022. URL: http://

journals.openedition.org/lirico/11794 ; DOI: https://doi.org/10.4000/lirico.11794

Este documento fue generado automáticamente el 7 enero 2022.

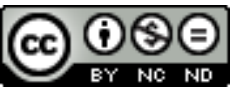

Cuadernos LIRICO está distribuido bajo una Licencia Creative Commons Atribución-NoComercialSinDerivar 4.0 Internacional. 


\title{
Escribir la historia de los futuros del pasado
}

\author{
Ecrire l'histoire des futurs du passé \\ Writing the History of the Futures of the Past
}

\section{Patrick Boucheron}

Tradución : Cecilia González

\section{NOTA DEL EDITOR}

En nombre de Cuadernos LIRICO, agradecemos el acuerdo del autor para traducir este ensayo. L'Histoire à venir, volumen donde fue publicado, reúne la versión escrita de dos conferencias realizadas por Patrick Boucheron y François Hartog en el marco del festival del mismo nombre, que tuvo lugar en la ciudad de Toulouse en mayo de 2017. Patrick Boucheron « Ecrire l'histoire des futurs du passé » en Patrick Boucheron \& François Hartog, L'Histoire à venir. Avant-propos de Corinne Bonnet \& Claire Judde de Larivière. Toulouse, Anacharsis, 2018, « Essais. Série Histoire », p. 14-41.

1 Walter Benjamin -a quien Hannah Arendt atribuía el don de "pensar poéticamente"fue inolvidablemente retratado por ella como un pescador de perlas. Era el que arrebataba al pasado "fragmentos de pensamiento" que reunía luego sobre sí mismo. "Al igual que un pescador de perlas que desciende hasta el fondo del mar, no para excavar el fondo y llevarlo a la luz sino para descubrir lo rico y lo extraño, las perlas y el coral de las profundidades y llevarlos a la superficie, este pensamiento sondea en las profundidades del pasado, pero no para resucitarlo en la forma que era y contribuir a la renovación de épocas extintas" (Arendt 2017: 212).

2 No se puede revivir el pasado porque la tradición, es decir, la autoridad del pasado que se nos presenta históricamente, se ha roto. Esta ruptura es irreparable y no es historiador, sin duda, quien no sea cabalmente consciente de esta transmisión quebrada. Es necesario, entonces, inventar, o reinventar, nuevas formas de tratar con el 
pasado. Puede denominarse "citabilidad" esta disposición del pasado a venir a acribillar con sus esquirlas nuestro presente, a incomodarlo alejándolo de esa "falsa paz" en la que permanentemente corremos el riesgo de hundirnos. Las perlas del brillante pescador de las profundidades no son solo citas brillantes sino hebras del tiempo donde brillan, por efracción, fulgores de porvenir. Recolectarlas para volverlas visibles, eso es lo que llamamos aquí: escribir la historia de los futuros del pasado.

3 No hay que preocuparse: es más fácil de lo que cabe imaginar. El gesto del pescador de perlas es el gesto, modesto y obstinado, del niño Walter Benjamin, que acumulaba en sus cajones tarjetas postales, solapas de sobres, listas, fotos escritas, papeles pegados y juguetes rusos. La colección siguió siendo siempre para Benjamin una insurrección infantil contra el orden del mundo. Clasifica, ficha, vuelve a copiar, marca con siglas minúsculas, pero todo esto para alimentar la "protesta obstinada contra lo típico, contra lo clasificable" (2011:153) ${ }^{1}$. Porque, dice en otro sitio, "yo, en cambio, no pensaba conservar lo nuevo, sino renovar lo antiguo" (1982: 105).

Por eso ya no podemos, a partir de Walter Benjamin, reconocernos en el optimismo historicista de los eruditos que, como el coleccionista Eduard Fuchs, piensan que el pasado está recogido "de una vez por todas en los graneros del presente" (Benjamin 1982: 100). La certeza sobre la "bendición de la cosecha" (100) es análoga a la certeza metodológica del historiador que finge creer que es suficiente acumular trazas del pasado para contribuir al progreso del conocimiento histórico. Pero también es la certeza, política, del "pathos democrático de 1830" (115), cuyas esperanzas están puestas en el progreso a secas. ¿Qué es lo que se juega aquí? Nada menos que la textura del tiempo que desbarata toda aplicación mecanicista de la causalidad en historia, cuando el historicismo postulaba la existencia de un "tiempo homogéneo y vacío". Ese mismo tiempo que las tesis Sobre el concepto de historia rechazan. Porque escribir la historia no significa conocerla "tal como fue" sino apoderarse de un recuerdo tal como "relampaguea en el instante de un peligro", solo podrá escribir la historia quien tenga "el don de encender la chispa de esperanza que [le] es inherente" (Benjamin 2012, p. 307-308, Tesis VI).

5 Pensemos, entonces, en lo que Cornelius Castoriadis hizo con la experiencia democrática ateniense, y lo que Grecia, a su vez, le devolvió. Cuando se interesó por los comienzos no se trataba en modo alguno para él de construir una ficción de los orígenes. Uno no se interesa en los Antiguos para encontrar a sus Antiguos, como los genealogistas, que se eligen Ancestros. Tampoco se trata de retornar a -o de retomarquién sabe qué tradición. Castoriadis no busca en el pasado modelos para imitar o un origen por alcanzar, sino lo que él llama "indicios de posibilidad", es decir la certificación de que ha existido en la historia una posibilidad -en este caso preciso, la autonomía política de la auto-institución- que debería poder reactivarse bajo una forma diferente.

6 Castoriadis calificaba de "germinal" esta perennidad virtual de ciertas realizaciones históricas, y en tal sentido la democracia griega era germinal y no paradigmática. Por eso podía leer a Tucídides y su Historia de la Guerra del Peloponeso como un clásico en el que Atenas aparece no como el punto de llegada sino como el punto de partida del relato. "Este punto de partida -lo que es extraño para el pensamiento en general y para el pensamiento político en particular- es activo; en alguna medida tiene una vida propia: sucede con la realidad política ateniense lo que sucede con un gran texto 
filosófico o una gran música, uno puede volver interminablemente a ellos y encontrar siempre algo nuevo" (Castoriadis 2011: 181).

7 No estamos lejos aquí de Hannah Arendt y de su capacidad de apropiación filosófica de la historia que no es, en el fondo, sino una filosofía práctica de la acción humana. Y si nos preguntan para qué sirve la historia, al menos podremos ponernos de acuerdo en esta definición simple, ni beata, ni desesperante: la historia es el arte de recordar aquello de lo que los hombres son capaces ${ }^{2}$. De lo mejor y de lo peor, evidentemente, y siempre en situación. Pueden encontrarse mil ejemplos, y no solamente en los libros de los historiadores. Pienso en este momento en una página sublime de $\mathrm{El} \mathrm{sargento} \mathrm{en} \mathrm{la}$ nieve de Mario Rigoni Stern: después de haber descrito los sufrimientos atroces de esa otra retirada de Rusia que fue la de los soldados italianos perdidos en el Frente Oriental de la Segunda Guerra, este escritor ebrio de fraternidad cuenta el día en que, aturdido de hambre y de frío, abrió sin pensar, y como en un último intento desesperado, la puerta de una isba donde unas mujeres y unos soldados rusos compartieron su comida con él sin pronunciar palabra, y lo dejaron partir luego. "La cosa fue muy simple: comprendí que los rusos eran como yo. En aquella isba se creó entre los soldados rusos, las mujeres, los niños y yo una armonía que distaba de ser una tregua. Trascendía con mucho el respeto que se tienen entre sí los animales del bosque. Por una vez las circunstancias permitieron que los hombres supieran ser hombres. ¿Dónde estarán ahora esos soldados, esas mujeres, esos niños? Ojalá todos hayan sobrevivido a la guerra. Mientras vivamos, todos los que estuvimos allí nos acordaremos de lo que pasó. Sobre todo los niños. Si aquello ocurrió una vez, puede ocurrir de nuevo. Dicho de otro modo, puede volverles a ocurrir a muchísimos hombres más y convertirse en una costumbre, en un modo de vida" (2013:135).

8 Si el pasado tiene una autoridad sobre nuestras vidas, no es porque las recargue con el peso de la tradición. Es porque ensancha nuestra experiencia, o mejor aún, porque reanima sin cesar la idea de experiencia y al hacerlo, la vuelve posible una vez más. Escribir la historia de esos futuros del pasado supone abrirse a otras vidas distintas de la nuestra y comprender que las vidas de los otros no son, por el solo hecho de ser lejanas o antiguas, más fácil o más simplemente asignables a categorías bien delimitadas. Son otras vidas que, por haber sido vividas, pueden serlo una vez más, y volvámoslo a decir, para lo mejor o para lo peor. Habría entonces dos maneras de negar la historicidad: abolir toda herencia y negar el pasado en nombre de la arrogancia del presente, pero también entregarse cuerpo y alma a la perpetuación de una tradición, dado que, en una perspectiva benjaminiana, la fidelidad a la tradición es en sí una catástrofe.

9 La noción de experiencia es sin duda la que permite hilvanar mejor los dos hilos del Festival de la Historia por venir que nos reúne, nos volverá a reunir, y reúne aquí mismo los textos de este volumen: la escritura de la historia, por un lado, las relaciones entre historia y democracia, por otro. En ambos casos se trata efectivamente de evocar el pasado ${ }^{3}$. Llamar el pasado ante nosotros, no para recitarlo, ni para entregarse obedientemente a un deber de memoria, sino para retomarlo y reactivar en él una potencia de convocación que trae el pasado al presente. Llamarlo ante nosotros sin que eso implique tirarlo para nuestro lado, en el sentido de hacerlo jugar en nuestro favor y mostrar que está con nosotros. Este es -hay que recordarlo- el uso más banal de la historia, arte de la celebración de los poderes y de quienes los adulan antes de ser técnica de emancipación para quien trabaja en no ser gobernado, no hasta tal punto al 
menos, por esos mismos poderes ${ }^{4}$. Se dirá sin duda que demorar el olvido es la tarea más banal, pero también la más imperiosa, de los historiadores. Decir que deben evocar el pasado es una manera de devolverlos a esa exigencia infantil y cerrada que también es, lo hemos visto, la de la colección; pero remite asimismo a la dimensión poética de la actividad historiadora, la única capaz de inventar de manera delicada y ociosa eso que es mucho más que un remontarse al pasado.

10 Así Frédéric Boyer, en Rappeler Roland, trae la figura heroica de la Chanson de Roland a un presente obsesionado por la guerra. Esta evocación de un relato muy antiguo tiene inevitablemente la fuerza de la invención y toma en cierta manera la forma de una reconstitución. Notemos de paso que esta manera de hacer de la literatura una práctica de la hospitalidad, que consiste en modelar el lugar donde el pasado se retrotrae a nuestro recuerdo, implica también una ética de la traducción, entendida como reciprocidad. Un texto antiguo es recibido, o acogido, en la lengua contemporánea que se ve transformada por esta convocación. Dicho de otro modo, traducir un texto antiguo es intentar restituir lo que la irrupción del pasado hace a nuestro presente. Esta es la verdadera batalla: "Haber perdido su pasado, aquello que sucedió y ya no existe ¿qué puede significar?" Y si la cuestión fuera, mucho más aún, que ningún pasado existe fuera del combate que nos atrevemos a librar contra él". Provendríamos del pasado, sí, pero “¿de qué pasado, sino del que nos contamos en presente?” (2013: 293).

11 Se tendría que poder jugar, maliciosamente, con esta exigencia. Maliciosamente es la palabra justa, porque la comicidad del título, Rappeler Roland, seguramente no es involuntaria; permite protegerse de la grandilocuencia que semejante ambición historiadora tiene, inevitablemente. Pienso aquí en un artículo de Bruno Latour irónicamente titulado "Llamada a revisión de la modernidad". El autor de Nunca fuimos modernos -que algunos toman por desfachatado cuando no es más que metódicamente inventivo- llama nuestra atención sobre el hecho de que cuando una empresa lanza al mercado un producto y luego descubre que es defectuoso, dice también que inicia una llamada a revisión. Y lo hace con gran despliegue publicitario, para convencer a los consumidores de que se preocupa por la calidad de los bienes. La antropología simétrica predicada por Bruno Latour consiste en historizar nuestro propio punto de vista, en desnaturalizarlo, pero no en destruirlo o abdicar de él. " 'Llamar la modernidad a revisión' para los europeos no puede querer decir que abandonarían la ambición de alcanzarla sino, al contrario que son conscientes, por fin, de su responsabilidad" (2005 web).

Esto es lo que nos reúne, entonces: una inquietud, sin duda, a la vez alegre y determinada, de esas que empujan para adelante, una inquietud en la que se mezcla el deseo de asumir las responsabilidades con el deseo de defender un cierto régimen de verdad. Y por eso esta inquietud, lejos de paralizar la acción a través de la duda, arranca las quietudes de la "falsa paz" donde se diluyen las voluntades colectivas. ¿Se trata de inventar la historia por venir? Sí, indudablemente, pero entonces habría que entender esta operación en el sentido medieval de la inventio: ahondar el sentido; buscar en él las trazas o los vestigios, es decir las huellas que el tiempo produce en las cosas. Lo que explica la atención atribuida por la edición inaugural de nuestro festival, sin duda, a la cuestión del dato: "del Sílex al Big Data". Ya que la historia por venir está menos por esperar que por constatar. Reclama atención más que especulación, espera simplemente que se constate su existencia, que se la considere, sobre todo, y que se quiera considerar que ya existe, no necesariamente en los lugares donde más se la 
espera, no siempre entre los que se celebra a grandes voces, no necesariamente en los espacios más legítimos, sino de manera frágil, discreta, endeble, fugaz. Identificar estas trazas exige paciencia y modestia, cierto compromiso en la elección de las cosas, método y fantasía, porque en última instancia habrá que imaginar todos esos relatos, no para fabularlos sino para producir imágenes.

¿Hace falta una, justamente, de lo que aquí se está argumentando? Es la de Cola di Rienzo, en Roma, al promediar el siglo XIV. Hijo de un tabernero y una lavandera, notario y letrado refinado, Cola di Rienzo encarna con brillo las posibilidades que ofrecen las sociedades urbanas de la Italia comunal, intensamente escolarizadas, que hacen del acceso al saber uno de los principales resortes del ascenso social. "Nadie sabía leer como él los antiguos epitafios. Traducía en lengua vulgar todas las inscripciones antiguas e interpretaba con precisión los epitafios antiguos", escribe sobre él el Anónimo romano de la Crónica -hoy diríamos que era un hábil epigrafista ${ }^{5}$. Vean cómo va en busca de las inscripciones de las ruinas de Roma, en el momento en que la ciudad, privada de la presencia de los Papas, quedó librada al apetito de los barones. Está sembrada de vestigios antiguos, en el centro, pero también muy lejos de la última casa medieval, lo que indica la espectacular desproporción de lo que fue el monstruo urbano de la Urbs en los tiempos de su esplendor antiguo. Al recorrer sus escombros, Cola di Rienzo es el caminante de la decadencia de Roma. Y puesto que sabe descifrar el lenguaje de las ruinas, Cola escucha los reproches que estas le hacen.

Cola tenía la firme intención de hacer resonar esos reproches en los oídos de los romanos, que no sabían leer, en los vestigios de su propia grandeza, los futuros del pasado. Esto es lo que declaró aquel día de 1346 en el que, en la basílica San Juan de Letrán, "exhortó al pueblo con un bello discurso en lengua vulgar", discurso duplicado en las "figuras" alegóricas que había hecho pintar. A través de las palabras, tanto como de las imágenes, se trataba entonces de traducir, y de volver por lo tanto visible y disponible, "una gran y magnifica placa de metal grabada con letras antiguas que nadie sabía leer ni interpretar" (Malherbe-Galy et Nardone, 2015: 162) ${ }^{6}$. Esta placa es la Lex regia, o Lex de imperio Vespasiani. ¿Pero qué decía esa inscripción grabada en el bronce que solo Cola lograba descifrar? Que el senado delegaba su soberanía en el emperador; lo que implica que esta seguía teniendo un origen popular. El pueblo la había confiado al emperador, en cualquier momento podía retomarla: este era entonces el mensaje político que Cola di Rienzo ponía a la vista de todos, en una genial puesta en escena de política arqueológica. Porque el papa Bonifacio VIII había dado vuelta la placa de bronce para utilizarla como mesa de altar en su basílica de Letrán (di Carpegna Falconieri 2012: 62). Al erigirla frente al pueblo, Cola di Rienzo la desacralizaba al mismo tiempo que restauraba su legibilidad.

El espejo que Cola di Rienzo ponía frente a sus conciudadanos era, sin lugar a dudas, ambiguo. ¿La Roma que los llamaba a admirar era la republicana o la imperial? Esa fue su trágica ambigüedad, la que precipitó seguramente su fracaso político. Subsiste, para nosotros, ese gesto que pone de manifiesto con un brillo inalterado lo que la historia es capaz de hacer cuando se preocupa por recoger las promesas no cumplidas que yacen a los pies de los hombres, degradadas, pero siempre disponibles. El gesto de Cola di Rienzo dando vuelta la mesa del altar de San Juan de Letrán, asumiendo el relevo del pasado para leer y traducir en voz alta, deja ver la potencialidad inacabada que el pasado reserva y que, sin Cola, hasta ese momento, seguía mirando al suelo. Por eso la excepcional competencia epigrafista de Cola di Rienzo, de la cual los historiadores no 
tienen ninguna razón para dudar, es el resorte principal de su toma de consciencia política (Petrucci 1993: 35). Gracias a ella, ese gran cadáver boca arriba que es la ciudad de Roma se convierte en un cuerpo escrito en el que vibran nuevamente todos sus futuros no acontecidos.

Esto es exactamente lo que hace Cola di Rienzo en el relato del Anonimo romano: recoge las trazas del pasado, pero las recoge literalmente, para alzarlas a la altura del porvenir que le inspiran. Este es el uso enérgico que hace de la antiquitas, esa parte del pasado que, porque no pasa, porque no está fuera de uso como puede estarlo la parte muerta de la vetustas, debe ser reasignada al presente de la acción política. En el fondo, la inventio que practica sigue siendo enteramente medieval. Surge del ejercicio del reempleo más que del de la conservación. No se trata de ninguna manera de transmitir tal cual una tradición -sería, en el sentido benjaminiano, catastrófico- sino de reinventarla. El pasado no sale indemne de lo que Frédéric Boyer llama, justamente, "el combate que nos atrevemos a librar con él" (2013). Perder para conservar, olvidar para recordar: esa es, profundamente, la lógica del reempleo, que siempre supone, por consiguiente, un sacrificio. Puesto que no todo puede superar la prueba del tiempo, puesto que es necesario, siempre, que haya pérdida, quien se proponga reutilizar los despojos del pasado tiene que resolverse a hacer distinciones dentro de esa herencia. Para dar cuenta de este movimiento dialógico, Jean-Claude Bonne sugirió el empleo de la noción de "relevo", que utilizo aquí (1989). El término es la traducción propuesta por Jacques Derrida de la Aufhebung de Hegel, que designa ese movimiento dialéctico por el cual el Espíritu, en sus figuras sucesivas, progresa hacia un grado cada vez mayor de razón (Derrida 2006). Cada una de sus etapas consuma el abandono del momento precedente y su reactivación sublimada por la actualización de una verdad que ya estaba ahí, pero de manera subterránea.

Por supuesto, las historiadoras y los historiadores de hoy deben, a su vez, hacer distinciones dentro de su herencia. Han dejado atrás la filosofía de la historia con la misma energía con la que se muestran intransigentes en su rechazo de extraer del tiempo pasado trozos útiles a la idea halagadora que se hacen de ellos mismos para encontrar "una verdad a [su] semejanza y a [su] única conveniencia", como escribía Lucien Febvre en 1919 (1920: 4) cuando se trataba de reafirmar la historia como ciencia contra sus apropiaciones asesinas. Porque en adelante es a todo el pasado, en bloque, sean cuales fueren los sentimientos que este les inspira, a lo que deben apuntar.

Y aun así, hay algo en el gesto de Cola di Rienzo que implica, para nosotros todavía, la dignidad de la historia, su energía y su voluntad propia. En el prólogo, el autor anónimo de la crónica que narra la aventura política de Cola di Rienzo no se limita, por otra parte, a explicar las razones por las cuales ha decidido volcar en lengua vulgar lo que ha visto y oído como "seguramente verdadero", "en pro de una utilidad y un placer comunes" (Anónimo romano 2015: 39). Remontando hasta los orígenes mitológicos de la escritura con Cadmos, el fundador legendario de Tebas a quien los griegos atribuían la invención del alfabeto fenicio, el Anonimo romano hace de la inscripción escrita una barrera contra el carácter falible de los recuerdos humanos. Pero esta memoria se inscribe in situ, "ubicad[a] entre los lugares célebres", "allí donde los hechos habían tenido lugar". Escribir la historia consiste entonces en desplazar para preservar de la usura del tiempo y demorar el olvido. "Me mantengo apartado", dice, pero estoy listo para cumplir esta tarea, porque "esta pena" también apacigua. Gracias a ella, sigue diciendo, "no percibo la guerra y los tormentos que se expanden por todo el país". 
19 Se puede entender este llamado a la consolación, porque permite también reencontrar un temor muy antiguo, o muy infantil, que nace de la desaparición de las cosas pasadas cuando permanecen fuera del alcance de una presencia observable y palpable. ¿Dónde va el presente cuando se convierte en pasado? ¿Dónde reside, dónde se esconde, dónde espera pacientemente que se lo releve? ¿Es posible que nuestras alegrías desvanecidas se hayan perdido para siempre? El temor nunca es vano porque, en ocasiones, al temer se previene. Pero nuestros temores antiguos ¿dónde están? ¿Dónde resurgirán las angustias que hemos experimentado, y que sin duda siguen su camino, subterráneamente, buscando en algún lugar sus puntos de resurgencia, como las fisuras del karst? ¿Y cuando los caminos se bifurcan, esas direcciones que no tomamos, las que trazaban futuros no acontecidos, no hay realmente ningún modo de retomarlas? Hay una historia juiciosamente ordenada, lisa como un friso, que permite dejar de plantearse estas preguntas. Una historia que bastaría con desplegar como se desenrolla un ovillo, y que convierte una serie de hechos en un encadenamiento de causalidades. Toda cronología es, desde este punto de vista, mentirosa, dado que encadena y arrastra, fecha tras fecha, a un relato que se da como inexorable cuando solo es la resultante, azarosa la mayoría de las veces, de la eliminación progresiva de todo lo que hubiera podido ser. Escribir la historia de los futuros del pasado equivale a desbaratar la falsa evidencia de esta linealidad.

¿Cómo pensar, entonces, la necesidad histórica de una línea quebrada? Tomemos, una vez más, un desvío. "En medio del camino de nuestra vida me encontré por una selva oscura, porque la recta vía era perdida". De la Comedia de Dante, Malcolm Lowry escribió una versión moderna y borrachina. Así calificaba él mismo Bajo el volcán, aparecido en 1947. Ustedes saben cómo caminan los borrachos: con un paso a la vez incierto y seguro. Después de una dura jornada llena de pruebas, el día de la fiesta de los muertos en una pequeña ciudad de México, el ex cónsul Geoffrey Firmin vuelve a su casa, embebido en whisky, en estado comatoso. Flota. No porque haya perdido el sentido de la orientación, no son caminos lo que le falta; al contrario, está rodeado de caminos posibles, de una impenetrable selva de caminos. La vía recta se ha perdido; ningún camino que no sea una dirección determinada. Se cita a Dante, pero podría citarse también Antígona de Sófocles, cuando el coro exclama en el verso 360: "Con todos los caminos a su disposición, sin camino, hacia nada camina". Lo que significa: el que es incapaz de perderse ya está perdido para siempre.

21 Y esta es la manera como describe Malcolm Lowry el andar del cónsul, que avanza titubeante: "as somehow, anyhow, they moved on". Esto no se traduce solamente como "de un modo u otro avanzan", sino como "de todos modos de algún modo avanzan" (Lowry 1973: 125). Personalmente me inclino a seguir la traducción inquieta de Clément Rosset en su breve tratado mordaz sobre la idiotez de lo real, que comienza por este ejercicio de microlectura. Para traducir somehow, anyhow, arriesga: "de una cierta, de todas maneras". Lo que está en juego aquí es la cuestión de lo cualquiera y de la necesidad. Si se puede hacer todo lo que se quiere, nunca se podrá hacer realmente cualquier cosa, dado que toda indeterminación se detiene en el umbral de la existencia. En cuanto vuelve sobre sus pasos, el cónsul se da cuenta de que ha caminado de una cierta manera, y que sus pasos trazan un camino, de esa manera. Y Clément Rosset comenta: "Llamamos insignificancia de lo real a esa propiedad inherente a toda realidad de ser siempre indistintamente fortuita y determinada". Esta es la profunda paradoja que la 
literatura revela a la filosofía: "Lo que hace versar la realidad en el sinsentido es precisamente la necesidad en la que se encuentra de ser siempre significante" (2004: 13).

Esta es la razón por la cual ya no podemos contentarnos con correr cuesta abajo la pendiente de una historia orientada. Lo que explica la reconsideración actual de la historia contrafáctica, que no se contenta con decir lo que fue, sino que proyecta o imagina lo que hubiera podido ser, arriesgándose a veces al procedimiento literario de un mensaje voluntario en el que el historiador intentaría imaginar lo que hubiera sucedido si Luis XIV no hubiera sido reconocido en Varennes y hubiera abandonado el reino de Francia, o si, por el contrario, no hubiera pensado en escaparse. Todo esto parece ser una suerte de libertad literaria que el historiador se permitiría, dando rienda suelta a la imaginación, abandonando con paso ligero los rigores del método. Sucede todo lo contrario. Pierre Singaravelou y Quintin Deluermoz mostraron que la historia es modelada por la hipótesis contrafáctica cuando toma en serio su naturaleza científica (2018). ¿El trabajo permanente de la ciencia no consiste, precisamente, en plantear hipótesis, en construir ecuaciones para cambiar sus variables, en imaginar experiencias de pensamiento preguntándose "qué es lo que hubiera pasado si"? La historia económica más modelizante, por ejemplo, no ha cesado de utilizar datos contrafactuales implícitos.

Solo una historia confiada en su solidez científica y lo suficientemente segura de sí misma para arriesgarse a la literatura puede hacer también la historia de los futuros no acontecidos, "desevidencializar" la historia, en algún modo. Es decir, recordar que en todo momento la historia es posible, que en todo momento estamos al filo de la navaja, que el transcurso político de las cosas nunca es fatal y que el historiador tiene la aspiración, a la vez política y poética, de retener el tiempo, es decir de llevar su escritura al momento en que las cosas no están jugadas de antemano. Esto es lo que, a mi entender, puede emparentar la construcción de la intriga histórica con las restantes formas de creación contemporánea. Esto es, en todo caso, lo que puede procurarle para el porvenir, el programa de una ambición que solo parecerá descabellada a quienes no vean que está hecha a la medida del peligro benjaminiano que se propone conjurar. El 6 de abril de 1980 aparecía en Le Monde una entrevista titulada "El filósofo enmascarado". Alguien se expresaba anónimamente en ella sobre el papel de los intelectuales en la sociedad francesa, en el momento en que todo el mundo sabía que Jean-Paul Sartre estaba muy enfermo (moriría nueve días más tarde, el 15 de abril de 1980). Había insistido ante los periodistas en que no dieran su nombre. “¿Por qué le he sugerido que utilicemos el anonimato? Por nostalgia del tiempo en el que, siendo yo totalmente desconocido, aquello que decía tenía alguna probabilidad de ser comprendido. Con el lector eventual, la superficie de contacto carecía de arrugas. Los efectos del libro repercutían en lugares imprevistos y dibujaban formas en las que yo no había pensado. El nombre es una facilidad" (1999: 218).

Quien así se expresaba iba a ser desenmascarado poco tiempo después de su muerte, cuatro años más tarde. Era Michel Foucault, que había escrito en 1969 “¿Qué es un autor?" y utilizado, a partir de los años 1970, numerosas estratagemas para intentar, siempre en vano, dejar de publicar libros en su propio nombre. Esta entrevista (que hoy se encuentra en Dits et Ecrits, dado que le ha sido reasignada) es una formidable crítica de lo que la notoriedad oscurece cuando lo que se dice empieza a contar menos que la personalidad de quien lo enuncia. Allí leemos algo que permite, me parece, iluminar un futuro posible: "Sueño con una nueva era de la curiosidad. Disponemos de los medios 
técnicos; el deseo está ahí; las cosas por saber son infinitas, la gente que se puede emplear en este trabajo existe. ¿De qué se padece? De demasiado poco: de canales estrechos, reducidos, casi monopólicos, insuficientes" (1999: 223).

Tal vez radique en esto lo que podría llamarse el carácter hugoliano de Foucault. Michel Butor ha descrito la "escritura pulpo" de Víctor Hugo: hace demasiado, habla demasiado, muestra demasiado, se expresa demasiado, escribe demasiado, quiere demasiado, sobrevive demasiado; en resumidas cuentas, "actúa demasiado: nos perturba, nos maltrata, nos arrastra, nos despierta los sueños a los que creíamos haber renunciado. En ese momento, sentimos que alguien nos está agarrando del pie." (2016: 12). De acuerdo, pero sin duda vale más, en realidad, hacer en exceso que no hacer lo suficiente. No hacemos lo suficiente. Escuchemos el grito que Sade lanza, rodeado de locos: franceses, un esfuerzo más si quieren ser republicanos. Un esfuerzo más, no para actuar, sino para ver y oír a todos los que actúan, a los que actúan con pertinencia, en su lugar, sin terminar nada a las apuradas, con calma y precisión, mejor aún, con más seriedad todavía. “¿De qué se padece? De demasiado poco”. Todavía es demasiado poco, estoy seguro de que podemos hacerlo mejor.

\section{BIBLIOGRAFÍA}

Anónimo romano, Chronique. Rome, le temps, le monde et la révolte de Cola di Rienzo, traducido del dialecto romano por Jacqueline Malherbe-Galy y Jean-Luc Nardone, introducción de Patrick Boucheron, Toulouse, Anacharsis, 2015.

Arendt, Hannah, Hombres en tiempos de oscuridad, Barcelona, Gedisa, 2017.

Benjamin,Walter, Infancia en Berlín hacia 1900, Madrid, Alfaguara, 1982.

- - -, "Historia y coleccionismo. Eduard Fuchs" en Discursos interrumpidos, Madrid, Taurus, 1982, p. 89-135.

- - -, Enfance. Eloge de la poupée et autres essais, Philippe Ivernel trad., Paris, Payot \& Rivages, 2011.

- - -, "Sobre el concepto de historia" en Obras. Libro I/vol. 2, Madrid, Abada Editores, 2012, p. 305-318.

Bonne, Jean-Claude, « Relève de l'ornementation celte païenne dans un Evangile insulaire du VII ${ }^{\mathrm{e}}$ siècle (Les Evangiles de Durrow) », en Ideologie et pratiche del reimpiego nell'Alto Medioevo. Atti della Settimana di studio del Centro italiano di studi sull'Alto medioevo (Spoleto, 16-21 aprile 1998), Spolete, Centro italiano di studi sull'Alto medioevo, 1999, p. 1011-1053.

Boyer, Frédéric, Rappeler Roland, Paris, P.O.L., 2013.

Castoriadis, Cornelius, Thucydide, la forcé et le droit. Ce qui fait la Grèce, 3. Séminaires 1984-1985 ("La création humaine ». Enrique Escobar, Myrto Gondicas y Pascal Vernay editores), Paris, Seuil, 2011.

Derrida, Jacques, “El pozo y la pirámide. Introducción a la semiología de Hegel” en Márgenes de la filosofía, Segunda Edición, Carmen González Marín trad., Madrid, Cátedra, 2006, p. 103-144.

Di Carpegna Falconieri, Tommasso, Cola di Rienzo, Roma, Salerno Editrice, 2002. 
Fèvre, Lucien, "L'histoire dans le monde en ruines", Revue de synthèse historique 30, 1920, p. 1-15.

Foucault, Michel, "El filósofo enmascarado" en Estética, ética y hermenéutica. Obras esenciales, Volumen III, Madrid, Paidós, 1999, p. 217-224.

Latour, Bruno, "Llamada a revisión de la modernidad", Revista de antropología iberoamericana. Ed. Electrónica. Número especial noviembre-diciembre, Madrid, Antropólogos iberoamericanos en red, trad. Alicia Criado, 2005.

Lowry, Malcolm, Au-dessus du volcan [1947], Stephen Spriel y Clarisse Francillon trad., Paris, Gallimard, 1973. Primera edición en español: Bajo el volcán, Raúl Ortiz y Ortiz trad., México, Ediciones Era, 1964.

Petrucci, Armando, Jeux de lettres. Formes et usages de l'inscription en Italie, XIe-XXe siècle, Monique Aymard trad., Paris, Editions de l'EHESS, 1993.

Rigoni Stern, Mario, El sargento en la nieve, Valencia, Pre-textos, trad. César Palma, 2007.

Rosset, Clément, Lo real. Tratado de la idiotez, Rafael del Hierro Oliva trad., Valencia, Pre-textos, 2004.

Singaravelou, Pierre y Deluermos, Quentin, Hacia una historia de los posibles: análisis contrafactuales y futuros no acontecidos, Buenos Aires, Editorial SB, 2018.

Widmaier, Carole, Fin de la philosophie politique? Hannah Arendt contre Leo Strauss, Paris, CNRS, 2012.

\section{NOTAS}

1. Cada vez que no se entregue detalle de la versión castellana del texto citada por P. Boucheron, se traducirá directamente del francés la referencia (N. de la T.)

2. Ver Carole Widmaier, Fin de la philosophie politique? Hannah Arendt contre Leo Strauss, 2012. Este párrafo y el que lo precede, sobre Castoriadis, se inspira en las palabras de Carole Widmaier y Paulin Ismard durante una sesión de un seminario que organicé con este último el 16 de mayo de 2017 sobre el tema "La política como 'forma de vida': en torno a la ciudad griega” (accesible en línea en la página del Collège de France).

3. La expresión utilizada por Patrick Bucheron es "rappeler le passé". El verbo "rappeler" significa "recordar" pero también "llamar" o "volver a llamar". Proponemos los términos “evocar" y "llamar" para traducirlo [N. de la T.].

4. Retomando la expresion de Michel Foucault: «Y propondría entonces, como primera definición de la crítica, la siguiente caracterización general: el arte de no ser tan gobernados" en ¿Qu'est-ce que la critique?, Henri-Paul Fruchaud y Daniele Lorenzini ed., 2015, p. 17.

5. Véase El Anónimo Romano, Chronique. Rome, le temps, le monde et la révolte de Cola di Rienzo, traducido del dialecto romano por Jacqueline Malherbe-Galy y Jean-Luc Nardone, 2015, p. 179 (retomo aquí algunos elementos de mi Introducción, p. 5-34).

6. Sobre este one man show de Cola en San Juan de Letrán, véase también Jean-Claude Maire Vigueur, L'autre Rome. Une histoire des Romains à l'époque communale (XIIe-XIVe siècle), 2010, p. 459. 


\section{AUTORES}

\section{PATRICK BOUCHERON}

Historiador

(Collège de France) 